\section{(c) (1) (8)}

OPEN ACCESS

Check for updates

\title{
LEST WE MISS IT: ANXIETY AND DEPRESSION SYMPTOMS IN ADULT PATIENTS WITH GENERALIZED TONIC CLONIC SEIZURES IN PAKISTAN
}

\begin{abstract}
${ }^{1}$ Department of Psychiatry, Combined Military Hospital, Kharian Cantt-Pakistan. 2 Department of Behavioral Sciences, Karakorum International University, Gilgit-Pakistan.
\end{abstract}

Address for correspondence: Sabih Ahmad

Department of Psychiatry, Combined Military Hospital, Kharian Cantt-Pakistan

E-mail:

sabihahmadpk@yahoo.com

Date Received:

December, $29^{\text {th }} 2020$

Date Revised:

December, $27^{\text {th }} 2021$

Date Accepted:

December, $28^{\text {th }} 2021$

Sabih Ahmad ${ }^{1 \times}$, Sadiq Hussain ${ }^{2}$, Tayyeba Kiran ${ }^{1}$, Anum Naz ${ }^{1}$

\section{ABSTRACT}

Objective: To find out the frequency of and compare anxiety and depression in epileptic and non-epileptic matched individuals.

Methodology: This cross sectional study was carried out at a tertiary care hospital in Pakistan including 200 epilepsy patients, visiting the department of medicine and psychiatry for follow-up. The second group consisted of 200 epilepsy free healthy matched individuals. Hospital anxiety and depression scale (HADS) was administered to assess participants' anxiety and depression. Means, frequencies, and Chi-square were applied to analyze the collected data

Results: Epilepsy patients were more likely to have depression $(\chi 2=33.56, p<.001)$ and anxiety $(\chi 2=55.96$, $p<.001$ ) as compared to the control group. Anxiety symptoms were found in $42 \%$, while depression in $34 \%$ of the patients. This was further distributed into mild, moderate and severe symptoms. Being unmarried, belonging to a particular age group, full time employment and a lower educational level were related with the anxiety symptoms while particular age group, lower educational level and full time employment with symptoms of depression.

Conclusion: The Generalized Tonic and Colonic Seizures (GTCS) epilepsy population has a significantly higher rate of comorbid anxiety and depression symptomatology.

Key Words: Anxiety; Depression; Epilepsy patients; Matched-group.

\section{INTRODUCTION}

Around 50 million people around the world suffer FROM epilepsy, $80 \%$ of them live in the developing countries including Pakistan. ${ }^{1}$ Here the prevalence of epilepsy is 9.99 per 1000 of the general population.? The commonest type worldwide remains Generalized Tonic Clonic Seizures 3 (GTCS).

Epilepsy shows no racial, age, gender or geographic boundaries. ${ }^{1}$ Social class has however been point to as an associated feature by some studies. ${ }^{4}$

Mental health professionals are well aware of the

This article may be cited as Ahmad S, Hussain S, Kiran T, Naz A. Lest we miss it: Anxiety and depression symptoms in adult patients with generalized tonic clonic seizures in pakistan. J Postgrad Med Inst 2021;35(3):152-6. https://doi.org/10.54079/ jpmi.35.3.2819. co-presence of various psychiatric illnesses in patients having epilepsy. ${ }^{5}$ The most commonly found being depression and anxiety disorders that are reported to be present in $10 \%$ to more than $55 \%$ of the patients. ${ }^{6}$ These psychiatric symptoms are now known to alter the severity of the epileptic illness ${ }^{7}$ causing poor control and increased hospitalization. ${ }^{8}$

Epilepsy can have biological, psychological and so- cial consequences that may contribute towards symptoms of anxiety or depression or both. ${ }^{9}$ Early onset of illness and seizure frequency, have been recently implicated as a cause of comorbid depression. ${ }^{4}$

High anxiety levels and low socio economic status have been linked with an individual's personal perception of stigmatization. ${ }^{10}$ Social and economical outfalls of having epilepsy may also contribute towards mental ill health. ${ }^{11}$

In the developing countries education may be discontinued after receiving a diagnosis of epilepsy. ${ }^{11}$ Furthermore, unemployment, discrimination at work and disturbed relationships may add on to the misery. Another possibility is the presence of primary psychiatric disorders before the onset of epilepsy. The psychiatric complications may be postulated as an interaction between disease process, anti epileptic drugs (AEDs) and psychosocial issues.

The co-presence of psychiatric disorders has been discussed in various studies. Being health profession- 
als in a third world country physicians face a huge patient to doctor ratio, and lesser time available for each patient that they see. Researchers wanted to know the magnitude of the problem in national population, so as to be vigilant right from the first hospital visit. Being ignorant of such co- morbidities in the people with epilepsy, may increase the intensity of their illness, functioning capacity and mortality. ${ }^{12}$

\section{METHODOLOGY}

This cross-sectional study was conducted at the departments of Medicine and Psychiatry in a tertiary care general hospital in Kharian, Pakistan, from September to December 2020, where consecutive 200 (166 men \& 34 women) patients having GTCS seizures reporting to the Medicine and Psychiatry outpatient departments (OPDs) were selected after consent. The inclusion criteria were an established diagnosis of GTCS and age 18 years or above. Subjects with an established co-morbid general medical condition other than and along with epilepsy, those having mental sub normality, patients suffering from any other psychotic disorder like schizophrenia, bipolar affective disorder etc., and patients who had positive family history of psychiatric illnesses were excluded from the study to remove bias.

A demographic proforma including relevant information was completed for every patient. This proforma included name, age, sex, address, employment status, type of employment, education, religion, marital status, duration of epilepsy, anti epileptic drugs (AEDs) being used and time period from the last fit.

Hospital Anxiety and Depression Scale (HADS) Urdu version ${ }^{13}$ a validated and reliable instrument, was used in screening the patients for anxiety and depression.

A healthy 'matched' group of 200 (122 men \& 78 women), individuals was also recruited from the families of affected patients, after taking informed consent. All efforts were made as much as possible to match them with patient group according to age, gender and social class. Sample size was calculated based on confidence level (95\%) and margin of error (5\%) that indicated 383 sample size needed. The data were calculated in Statistical Package for the Social Sciences (SPSS) version 21. Descriptive statistical technique: mean, standard deviation, and frequency were used to describe research sample and summarized data and inferential statistical technique-Chi-square-was applied to test the research hypotheses. In testing hypothesis, the level of $p \leq 0.05$ was considered significant. The former included means, standard deviations, and frequencies, and latter chi-square technique. The approval for the research was obtained from the ethics review committee of the hospital.

\section{RESULTS}

In our study, we included two demographically comparable groups of participants, 200 patients having generalized tonic-clonic seizures (166 men \& 34 women) and 200 epilepsy free individuals (122 men \& 78 women) as the control group. Further details of both groups are presented in Table 1.

To investigate whether patients having epilepsy and the matched group differed in the prevalence of depression and anxiety symptoms or not, chi-square test was used. Results indicated that patients having GTCS were more likely to have depression $\left(\chi^{2}=\right.$ $33.56, p<.001)$ and anxiety $(\chi 2=55.96$, $\mathrm{p}<.001)$ as compared to the control group.

Gender based comparison was also performed between patients and control group. Results reported in Table 2, revealed that both male and female patients reported higher level of depression and anxiety as compared to males and females in control group.

Patients' demographic results revealed that gender $(\alpha 2=1.03, p>.05)$, marital status $(\chi 2=.78, p>.05)$, and occupational status $(\chi 2=1.0, p>.05)$ did not significantly relate with their reported level of depression symptoms. Gender ( $\chi 2=1.56, p>$.05) was also not found associated with anxiety symptoms. Patients' marital status $(\chi 2=18.7$, $p<.001)$, age $(\chi 2=25.1, p<.001)$, occupation $(\chi 2=5.97, p<.05)$, and education $(\chi 2=$ $21.3, p<.001)$ were significantly related with their reported level of anxiety symptoms and their age $(\chi 2=5.9, p<.05)$ and education $(\chi 2=13.0, p<.001)$ were also related with the depression symptoms.

Unmarried patients were more likely to have anxiety as compared to married patients. Younger patients were more likely to have depression symptoms while oldest tier in the patients reported higher frequency of anxiety symptoms than other patients. Employed patients were more likely to have anxiety and depression symptoms than unemployed ones. Literate patients were more likely to have depression and anxiety symptoms than uneducated and more educated patients.

\section{DISCUSSION}

As already known our study found out that epilepsy patients in Pakistan too, were more likely to have anxiety and depression symptoms as compared to their healthy counterparts. Available data showed prevalence of symptoms of depression in $7.5 \%$ to $80 \%$ patients. ${ }^{7,9,12}$ Similarly, anxiety was found in $10 \%$ to over $40 \%$ of similar patients, ${ }^{14,15}$ which is in agreement with our findings. However, in our study 33\% patients scored in the morbid range of both anxiety and depression symptoms.

We found the age of the patient associated significantly with both anxiety and de- 
Table 1: Demographic Characteristic Of Epilepsy Patients And Matched Group

\begin{tabular}{|c|c|c|c|c|c|c|c|}
\hline \multirow{2}{*}{ Variable } & \multicolumn{3}{|c|}{ Patients $(\mathrm{n}=200)$} & \multicolumn{3}{c|}{ Matched Group $(\mathrm{n}=200)$} \\
\cline { 2 - 7 } & Males (166) & Females (34) & Total (200) & Males (122) & Females (78) & Total (200) \\
\hline \multicolumn{2}{|c|}{ Mean Age } & $34.37 \pm 14.92$ & $34.43 \pm 13.25$ & $34.38 \pm 14.08$ & $34.9 \pm 12.9$ & $30.85 \pm 12.58$ & $32.87 \pm 12.74$ \\
\hline \multirow{2}{*}{ Marital Status } & Married & $120(72 \%)$ & $26(76 \%)$ & $146(73 \%)$ & $92(75 \%)$ & $42(54 \%)$ & $134(67 \%)$ \\
\cline { 2 - 7 } & Unmarried & $46(28 \%)$ & $8(24 \%)$ & $54(27 \%)$ & $30(25 \%)$ & $36(46 \%)$ & $66(33 \%)$ \\
\hline \multirow{3}{*}{\begin{tabular}{c} 
Working status \\
\cline { 2 - 7 }
\end{tabular}} & $\begin{array}{c}\text { Employed (part \& } \\
\text { full time) }\end{array}$ & $136(82 \%)$ & $5(15 \%)$ & $141(71 \%)$ & $82(67 \%)$ & $2(3 \%)$ & $84(42 \%)$ \\
\cline { 2 - 7 } $\begin{array}{c}\text { Education Level } \\
\text { (years of schooling) }\end{array}$ & Unemployed & $30(18 \%)$ & $29(85 \%)$ & $59(29 \%)$ & $40(33 \%)$ & $76(97 \%)$ & $116(58 \%)$ \\
\cline { 2 - 7 } & Uneducated & $21(13 \%)$ & $10(29 \%)$ & $31(15 \%)$ & $4(3 \%)$ & $32(41 \%)$ & $36(18 \%)$ \\
\cline { 2 - 7 } & Literate (5-8 years) & $70(42 \%)$ & $19(56 \%)$ & $89(45 \%)$ & $54(44 \%)$ & $42(54 \%)$ & $96(48 \%)$ \\
\hline
\end{tabular}

Table 2: Analysis Of Prevalence Of Depression And Anxiety In Epilepsy Patients And Matched Group

\begin{tabular}{|c|c|c|c|c|c|c|c|c|}
\hline \multirow{2}{*}{ Variable } & \multicolumn{4}{|c|}{ Depression } & \multicolumn{4}{|c|}{ Anxiety } \\
\hline & Yes & No & $\chi^{2}$ & $\mathrm{p}$ & Yes & No & $\chi^{2}$ & $\mathrm{p}$ \\
\hline Epilepsy Patients & 68 & 132 & \multirow{2}{*}{33.56} & \multirow{2}{*}{$<0.01$} & 84 & 116 & \multirow{2}{*}{55.96} & \multirow{2}{*}{$<0.01$} \\
\hline Matched Group & 20 & 180 & & & 18 & 182 & & \\
\hline
\end{tabular}

pression symptoms. The highest incidence of anxiety was found in the age group of over 55 years. The little sample that we had from this group in the patient group was almost all (25 out of 27 ) found to be suffering from symptoms of anxiety. Although this was the smallest group in our data $(\mathrm{n}=27)$, and could be a source of bias. This finding was in contrast to the previous findings, where younger age had been associated with anxiety in epilepsy. ${ }^{16}$ We also found an association between patients' age, a particular bracket of 15 to 34 years, and depression contrary to previous studies where age was not associated with depressive symptoms. ${ }^{17}$ An interesting finding to note here is that very few (5 out of 27 ) of the eldest age group in our sample reported depressive symptoms if at all, as compared to $100 \%$ of them reporting anxiety symptoms.

Lower education level attained by the participants was found associated with anxiety symptoms, in patients with 5 to 8 years of schooling. This finding is in agreement with previous similar report from Brazil. ${ }^{18}$ Previous studies also support our findings of increased risk of developing depressive disorders in participants who did not complete their high school. ${ }^{19}$
In past studies unmarried patients with epilepsy were found to be at a higher risk of developing psychiatric symptoms ${ }^{20}$ whereas our study showed no significant difference between married and unmarried individuals. Anxiety symptoms were however significantly higher in the unmarried population, a finding not supported elsewhere.

Previously psychiatric symptoms were associated with being unemployed in the patients having epilepsy. ${ }^{16}$ But our findings found increasing association of anxiety related symptoms as the employment status of the individual improved from being part time to full time. Depressive symptoms were also associated with full time employed in Pakistan, contrary to unemployment in previous findings elsewhere. ${ }^{21}$

The degree of depression symptoms could be compared with only one previous study available to us. ${ }^{22}$ This quoted quite comparable $29.8 \%$ of mild and $17.4 \%$ moderate and $0.9 \%$ severe intensity symptoms, with our $57 \%, 34 \%$ and $9 \%$ respectively.

The existing literature pointed towards an increased risk in females for developing anxiety or depression, which was not in agree- ment with our findings. ${ }^{21}$ The overall number of women in our sample was however smaller than the men, which could have led to a possible bias.

In our study a larger proportion of the sample were on combination therapy, which could be a confounding factor, but requires further research to be authenticated. An integrated approach is required to treat patients with epilepsy due to the high risk of developing psychiatric comorbidities. Further research in different types of epilepsy and relation of psychiatric disorders with different lesions and AEDs, individually and in combination may be undertaken.

Although the male to female population is almost 1:1 in our country but the number of male subjects in our study were almost three times more than the females. ${ }^{23}$ This was due to the simple fact that more males were reporting to the hospital than females.

\section{CONCLUSION}

Our results indicated that anxiety \& depression are common among epilepsy patients. Awareness of the same amongst the health care staff is necessary for an earli- 
er diagnosis of psychiatric morbidity and thwarting further disability. It is proposed that depression and anxiety should be studied as a symptom of the syndrome of epilepsy.

\section{-ACKNOWLEDGMENTS}

We are thankful to Professor David B Mumford, for allowing us to use HADS Urdu version.

\section{REFERENCES}

1. World Health Organization. Media Center, Fact Sheets [online] 2019. [cited 2020 Dec 19]. Available from: URL: https://www.who.int/news-room/fact sheets/detail/epilepsy

2. Khatri IA, lannaccone ST, llyas MS, Abdullah M, Saleem S. Epidemiology of Epilepsy in Pakistan: review of literature. J Pak Med Assoc. 2003; 53(12):594-6.

3. Aziz H, Güvener A, Akhtar SW, Hasan KZ. Comparative epidemiology of epilepsy in Pakistan and Turkey: population-based studies using identical protocols. Epilepsia. 1997; 38(6):716-22.

4. Asadi-Pooya AA, Kanemoto K, Kwon OY, Taniguchi G, Dong Z, Chinvarun Y, et.al. Depression in people with epilepsy: How much do Asian colleagues acknowledge it? Seizure. 2018; 57:45-9. doi: 10.1016/j.seizure.2018.03.012.

5. Ayanda KA, Sulyman D. The predictors of psychiatric disorders among people living with epilepsy as seen in a Nigerian Tertiary Health Institution. Niger Med J. 2016; 57(1):24-30. doi: 10.4103/0300-1652.180559.

6. Baker DA, Caswell HL, Eccles FJR. Self-compassion and depression, anxiety, and resilience in adults with epilepsy. Epilepsy Behav. 2019; 90:154-161. doi: 10.1016/j.yebeh.2018.11.025.

7. Josephson CB, Lowerison M, Vallerand I, Sajobi TT, Patten S, Jette N, et al. Association of Depression and Treated Depression with Epilepsy and Seizure Out- comes: A Multicohort Analysis. Neurol. 2017; 74(5):533-539. doi: 10.1001/ jamaneurol.2016.5042.

8. Mendez MF, Cummings JL, Benson DF. Depression in epilepsy. Significance and phenomenology. Arch Neurol. 1986; 43(8):766-70. doi: 10.1001/archneur.1986.00520080014012.

9. Błaszczyk B, Czuczwar SJ. Epilepsy coexisting with depression. Pharmacol Rep. 2016; 68(5):1084-92. doi: 10.1016/j.pharep.2016.06.011. PMID: 27634589.

10. Lee GH, Lee SA, No SK, Lee SM, Ryu JY, Jo KD, et al. Factors contributing to the development of perceived stigma in people with newly diagnosed epilepsy: A one-year longitudinal study. Epilepsy Behav. 2016; 54:1-6. https://doi. org/10.1016/j.yebeh.2015.10.024

11. Kanner AM. Psychiatric comorbidities in new onset epilepsy: Should they be always investigated? Seizure. 2017; 49:79-82. doi: 10.1016/j.seizure.2017.04.007.

12. Tao K, Wang $X$. The comorbidity of epilepsy and depression: diagnosis and treatment. Expert Rev Neurother. 2016; 16(11):1321-1333. doi: 10.1080/14737175.2016.1204233.

13. Mumford DB, Tareen IA, Bajwa MA, Bhatti MR, Karim R. The translation and evaluation of an Urdu version of the Hospital Anxiety and Depression Scale. Acta Psychiatr Scand. 1991; 83(2):815. doi: 10.1111/j.1600-0447.1991. tb07370.x.

14. Borgmann $M$, Holtkamp $M$, Adli $M$, Behr J. Depression und Epilepsie: Zwei Krankheitsbilder mit gemeinsamen Ursachen? [Depression and epilepsy: Two clinical pictures with common causes?]. Nervenarzt. 2016; 87(7):724-30. German. doi: 10.1007/s00115-0150026-4.

15. Hingray $C$, McGonigal A, Kotwas I, Micoulaud-Franchi JA. The Relationship Between Epilepsy and Anxiety Dis- orders. Curr Psychiatry Rep. 2019; 21(6):40. doi: 10.1007/s11920-0191029-9.

16. Munger Clary HM, Snively BM, Hamberger MJ. Anxiety is common and independently associated with clinical features of epilepsy. Epilepsy Behav. 2018; 85:64-71. doi: 10.1016/j.yebeh.2018.05.024.

17. Kuladee S, Prachason T, Srisopit P, Trakulchang D, Boongird A, Wisajan P, et al. Prevalence of psychiatric disorders in Thai patients with epilepsy. Epilepsy Behav. 2019; 90:20-24. doi: 10.1016/j. yebeh.2018.11.004.

18. Stefanello S, Marín-Léon L, Fernandes PT, Li LM, Botega NJ. Depression and anxiety in a community sample with epilepsy in Brazil. Arq Neuropsiquiatr. 2011; 69(2B):342-8. doi: 10.1590/ s0004-282x2011000300015.

19. Vujisić S, Vodopić S, Radulović L, Injac-Stevović L. Psychiatric comorbidities among patients with epilepsy in Montenegro. Acta Clin Croat. 2014; 53(4):411-6.

20. Vallée C, Biraben A, Nica A, Loiseau M. Épidémiologie et facteurs associés au syndrome dépressif chez les patients suivis au centre hospitalo-universitaire de Rennes pour une épilepsie [Epidemiology and associated factors with depression among people suffering from epilepsy: A transversal French study in a tertiary center]. Encephale. 2019; 45(1):40-45. French. doi: 10.1016/j. encep.2017.12.008.

21. Elghazouani F, Aarab C, Faiz F, Midaoui A, Barrimi M, Elrhazi K, et al. Troubles psychiatriques et facteurs associés chez une population de patients épileptiques à Fès, Maroc [Psychiatric disorders and associated factors in patients with epilepsy in Fez, Morocco]. Encephale. 2015;41(6):493-8. French. doi: 10.1016/j.encep.2013.06.004.

22. Engidaw NA, Bacha L, Kenea A. Prevalence of depression and associated 
factors among epileptic patients at Ilu Ababore zone hospitals, South West Ethiopia, 2017: a cross sectional study. Ann Gen Psychiatry. 2020; 19:19. doi: 10.1186/s12991-020-00268-5.

23. World Bank. Population, female (\% of total), Data [online]. 2020 [cited 2020

Dec 21]. Available from: URL: https:// data. worldbank.org/indicator/SP.POP.

TOTL.FE.ZS.

\section{Author's Contribution}

SA concieved the study, SH was responsible for designing, running tests and write up of the results of the study, TK and AN helped in data collection and write up the manuscript. Authors agree to be accountable for all aspects of the work in ensuring that questions related to the accuracy or integrity of any part of the work are appropriately investigated and resolved.

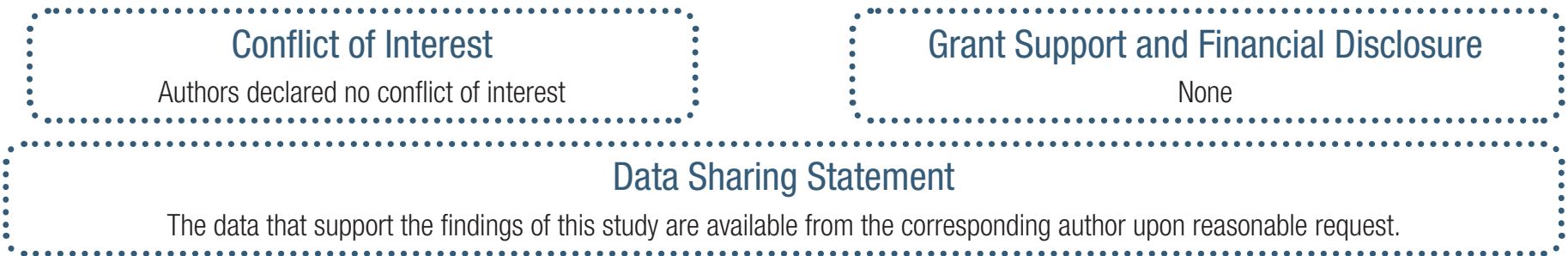

